\title{
Deformations of foundations of windplant installation crane sites and their reasons
}

\author{
Saulius Gadeikis ${ }^{1}$, Donatas Urbaitis ${ }^{2}$, Domas Gribulis ${ }^{3}$, Sonata Gadeikyte ${ }^{4}$, Gintaras Žaržojus ${ }^{5}$ \\ 1, 3, 4, 5 Department of Hydrogeology and Engineering Geology, Faculty of Chemistry and Geosciences, \\ Vilnius University, Vilnius, Lithuania \\ ${ }^{2} J S C$ “Geotestus”, Vilnius, Lithuania \\ E-mail: ${ }^{1}$ saulius.gadeikis@gf.vu.lt (correspondingauthor)
}

\begin{abstract}
Road and foundation deformations in modern Lithuanian construction are one of the most important problems. Constantly rising conflicts between customers and builders due to poor quality of foundations show that Lithuanian road builders do not ensure proper quality of work, do not perform the necessary road foundations and research, do not carry out continuous control of their work. One such example was the construction of the Pagegiai wind farm in $2014 \div 2015$. Improperly installed road and crane installation foundations have forced the wind power plant to stop working, which resulted in enormous losses. Additional cluster engineering geological surveys that included a full range of field and laboratory work made it possible to identify the causes of poor quality work and to properly assess the properties of substrates and primers that are important for safe foundation operation.
\end{abstract}

Keywords: permeability, hydraulic conductivity, moisture content, investigations.

\section{Introduction}

Wind power generation is one of the fastest growing areas of renewable energy sources in Lithuania. This type of electricity production requires large investment in construction. This applies not only to the construction of the base of each wind power plant, but also to the construction of temporary sites for access roads and installation cranes. The installation of each wind power plant is a complex and costly technological process, which takes place in accordance with extremely strict technical requirements. One of these requirements is to properly prepare the foundations of the installation crane sites so that they would be able to withstand the prescribed crane loads and perform safe installation work. Alongside with the wind power plant base projects, the installation crane site projects are also prepared according to the requirements of the wind power plant manufacturer and installer for the site foundations. The foundations of the sites must be long-lasting, withstand the required loads, be resistant to cold, be able to absorb the temporary surface water very quickly, and have a drainage system.

Requirements of access roads and crane platfrom for Enercon wind turbine E-101 for the site foundations: bearing capacity $>185 \mathrm{kN} / \mathrm{m}^{2}$, soil secondary load modulus of defor-mation $E_{v 2} \geq 45 \mathrm{MN} / \mathrm{m}^{2}$, drainage layer above it (sandy soil) $-E_{v 2} \geq 80 \mathrm{MN} / \mathrm{m}^{2}$, compaction index $D_{p r} \geq 100 \%$, upper asphalted part $-E_{v 2} \geq 100 \mathrm{MN} / \mathrm{m}^{2}, D_{p r} \geq 100 \%$, ratio of all layers $E_{v 2} / E_{v 1} \leq 2.3$.

\section{Deformations of installation crane sites and investigation programme}

During the summer-autumn of 2014, the construction work of the wind farm base was carried out, temporary access roads and crane sites were arranged. In the autumn of 2014, construction work was recognized as suitable and commissioned by the wind power plant installers. Some of the wind power plants were being installed until late autumn and there were no deformations of the base observed. In March 2015, after the installation work were renewed, strong deformations of the foundation against the design strength requirements were noticed on some installation crane sites. Repeated investigations of deformation properties of the foundations were carried out. The investigations were carried out by plate load test (LST 1360.5:1995). 
Table 1. Data of static plate tests carried out in March 2015

\begin{tabular}{|c|c|c|c|}
\hline $\begin{array}{c}\text { Wind power plant } \\
\text { No. }\end{array}$ & $\begin{array}{c}\text { Primary load modulus of deformation } \\
E_{v 1}, \mathrm{MN} / \mathrm{m}^{2}\end{array}$ & $\begin{array}{c}\text { Secondary load modulus of deformation } \\
E_{v 2}, \mathrm{MN} / \mathrm{m}^{2}\end{array}$ & $E_{v 2} / E_{v 1}$ ratio \\
\hline 12 & 32.7 & 98.7 & 3.02 \\
\hline 12 & 43.7 & 127.4 & 2.92 \\
\hline 12 & 50.5 & 124.5 & 2.46 \\
\hline 14 & 18.3 & 116.9 & 6.40 \\
\hline 14 & 26.2 & 103.0 & 3.93 \\
\hline 14 & 12.7 & 170.0 & 13.39 \\
\hline 15 & 19.6 & 224.6 & 11.43 \\
\hline 15 & 35.8 & 135.6 & 3.78 \\
\hline 22 & 26.8 & 168.6 & 6.28 \\
\hline 22 & 13.9 & 186.2 & 13.36 \\
\hline 22 & 51.9 & 130.6 & 2.52 \\
\hline 24 & 18.0 & 209.5 & 11.62 \\
\hline 24 & 21.0 & 101.6 & 4.83 \\
\hline
\end{tabular}

The investigations showed that on some sites, the plate load test (PLT) ratio between the secondary load modulus of deformation $E_{v 2}$ and the primary load modulus of deformation $E_{v 1}$ ranged from 2.46 to 13.36 times (see Table 1).

The installation work was stopped because the deformations of the foundation posed a risk of accidents during the installation of the cranes. Presumed causes of deformations: it is believed that after the winter season, under frost and surface water influence, the site foundation soil lost its strength, that is, it "self-decompacted". However, no such "self-decomposition" should occur having properly prepared the foundation. There was suspicion that the base construction was defective, bad quality.

In the summer of 2015, engineering geological investigations were carried out in order to determine the causes of deformation of the foundations. The investigations were aimed at assessing the state of the existing soil under the compacted layer, its physical and filtration properties, thickness, composition, physical properties and the state of the compacted layers as well as the state of the drainage system. For this purpose, the following work was foreseen: using DPL (Dynamic Penetration Test Light), to perform probing tests on natural soil. It was expected to obtain the compaction rate $I_{d}$, which would allow to evaluate the quality of compaction throughout the compacted soil section, to dig out the excavations at the drainage sites, to inspect and evaluate them, to take soil samples from all layers of the coating (gravel, cold-resistant soil), to determine their condition and physical properties, to make filling tests in the top layer of the foundation (broken stone) seeking to evaluate its true filtration properties.

\section{Conducted investigations and their results}

\section{Grain size distribution}

In July 2015, samples of gravel and cold-resistant layer from the installation crane sites (No. 1, 2, 6, 11, 18, 19) were taken and their grain size distribution and hydraulic conductivity $k_{10}$ were determined at the laboratory. Table 2 shows the aggregate data of the grain size distribution of gravel and cold-resistant soil.

The grain size distribution of gravel was performed from the arranged installation crane sites (No. 1, 2, 6, 11, 18, 19) out. These tests were carried out in order to determine its compliance with IT SBR 07. The tests were carried out according to LST EN 933-1:2012. According to technical requirements of minerals for car roads in Lithuania, the maximum amount of fine particles in the soil should not exceed 5\%. Allowance for fine particles in soil $(<0.063 \mathrm{~mm})$ in all tested samples is above the permitted limit of 5\%.

According to TRA MIN 07 (Section II, p. 13, Table 1), the maximum amount of fine particles in the cold-resistant soil must not exceed 3\%. The grain size distribution of this soil also showed that the permissible amount of fine particles in the soil is exceeded up to 3 times. The maximum amount (No. 2, 11, 18 and 19), in the remaining ones - the amount of fine particles is close to the permissible fine particle limit.

\section{Permeability tests or excavation filling tests}

Filtering aeration zone tests in the required depth excavations were carried out with an infiltrometer consisting of two rings (outer and inner) with diameters equal to $0.92 \mathrm{~m}$ and $0.452 \mathrm{~m}$ respectively and two "Marioto" vessels for constant pressure and water filtering. The infiltrometer rings are pressed into the soil $2 \div 3 \mathrm{~cm}$. The bottoms of the rings are filled with $1 \div 2 \mathrm{~cm}$ thick pebble so that the sandy and clay particles of the excavation bottoms are not washed out 
when pouring water into them. During the tests, the inclusions were made according to a stationary scheme, when both water rings are formed and maintained at a constant water level (compression). The results are presented in Table 3.

Table 2. The results of grain size distribution of gravel and cold-resistant layer

\begin{tabular}{|c|c|c|c|c|c|c|c|c|c|c|c|c|c|c|}
\hline \multirow{2}{*}{ 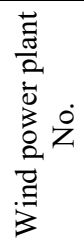 } & \multirow[b]{2}{*}{ 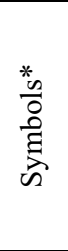 } & \multicolumn{13}{|c|}{ Grain size distribution, $\%$} \\
\hline & & $\begin{array}{l}\Omega \\
\stackrel{0}{0} \\
\dot{0} \\
V\end{array}$ & 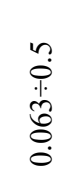 & $\frac{0}{\not 1}$ & $\stackrel{\circ}{\stackrel{0}{e}}$ & $\begin{array}{l}0 \\
\dot{+} \\
\dot{b} \\
\dot{1}\end{array}$ & $\begin{array}{l}b \\
\dot{v} \\
\dot{b} \\
\dot{+}\end{array}$ & $\begin{array}{l}0 \\
\infty \\
\dot{0} \\
\dot{b} \\
\dot{r}\end{array}$ & 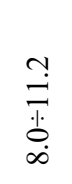 & $\begin{array}{l}\stackrel{0}{0} \\
\stackrel{1}{*} \\
\stackrel{+}{\sim} \\
=\end{array}$ & 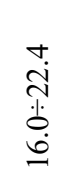 & $\begin{array}{l}n \\
\stackrel{n}{n} \\
\dot{v} \\
\dot{v} \\
\stackrel{\sim}{v}\end{array}$ & 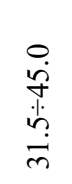 & $\begin{array}{l}0 \\
\ddot{y} \\
\wedge\end{array}$ \\
\hline 1 & $\mathrm{Gr}$ & 8.4 & 12.1 & 4.7 & 7.6 & 7.1 & 4.3 & 6.1 & 6.8 & 9.1 & 10.0 & 10.0 & 13.1 & 0.6 \\
\hline 1 & $\mathrm{Sa}$ & 2.3 & 71.9 & 9.5 & 5.5 & 3.4 & 1.6 & 1.5 & 1.2 & 1.5 & 0.5 & 1.1 & 0 & 0 \\
\hline 2 & $\mathrm{Gr}$ & 8.9 & 11.1 & 4.2 & 6.7 & 6.4 & 4.0 & 5.6 & 6.5 & 8.9 & 10.2 & 11.8 & 8.7 & 6.8 \\
\hline 2 & $\mathrm{Sa}$ & 6.6 & 53.8 & 13.5 & 9.1 & 6.4 & 2.9 & 2.7 & 1.5 & 2.9 & 0.6 & 0 & 0 & 0 \\
\hline 2 & $\mathrm{Sa}$ & 3.0 & 86.9 & 4.7 & 2.2 & 13.3 & 0.4 & 0.4 & 0.3 & 0.2 & 0.5 & 0 & 0 & 0 \\
\hline 6 & $\mathrm{Gr}$ & 8.6 & 11.6 & 3.6 & 5.8 & 7.6 & 6.3 & 10.8 & 5.9 & 12.1 & 6.5 & 8.6 & 10.7 & 1.9 \\
\hline 6 & $\mathrm{Sa}$ & 3.2 & 33.4 & 22.2 & 15.1 & 10.3 & 4.3 & 3.9 & 2.6 & 3.2 & 0.9 & 0.8 & 0 & 0 \\
\hline 11 & $\mathrm{Gr}$ & 7.6 & 10.0 & 4.4 & 6.8 & 8.4 & 6.5 & 9.6 & 10.1 & 12.5 & 10.2 & 7.2 & 4.6 & 2.1 \\
\hline 11 & $\mathrm{Sa}$ & 5.9 & 40.2 & 13.9 & 11.7 & 10.4 & 4.6 & 4.6 & 3.4 & 2.8 & 1.0 & 0.8 & 0 & 0 \\
\hline 18 & $\mathrm{Gr}$ & 7.9 & 8.7 & 3.4 & 5.4 & 4.9 & 3.3 & 4.7 & 6.1 & 9.2 & 9.6 & 13.6 & 19.7 & 3.4 \\
\hline 18 & $\mathrm{Sa}$ & 9.0 & 37.0 & 11.8 & 7.7 & 7.3 & 4.2 & 4.8 & 5.1 & 5.2 & 4.7 & 3.2 & 0 & 0 \\
\hline 19 & $\mathrm{Gr}$ & 8.9 & 8.4 & 3.3 & 6.2 & 9.0 & 6.5 & 8.7 & 9.0 & 11.8 & 11.5 & 9.0 & 6.6 & 1.1 \\
\hline 19 & $\mathrm{Sa}$ & 6.2 & 43.3 & 16.0 & 11.3 & 8.9 & 3.8 & 3.8 & 2.6 & 2.5 & 1.6 & 0 & 0 & 0 \\
\hline
\end{tabular}

${ }^{*} \mathrm{Gr}$ - gravel, $\mathrm{Sa}-$ sand or cold-resistant layer.

Table 3. The results of filling into gravel and cold-resistant layer (immediately beneath gravel)

\begin{tabular}{|c|c|c|}
\hline Wind power plant No. & Symbols & $\begin{array}{c}\text { Hydraulic conductivity } \\
k, \mathrm{~m} / \mathrm{d}\left(T=10^{\circ} \mathrm{C}\right)\end{array}$ \\
\hline 22 & $\mathrm{Gr}$ & 0.0073 \\
\hline 22 & $\mathrm{Sa}$ & 9.39 \\
\hline 19 & $\mathrm{Sa}$ & 0.09 \\
\hline 18 & $\mathrm{Gr}$ & 0.0280 \\
\hline 11 & $\mathrm{Gr}$ & 0.0030 \\
\hline 9 & $\mathrm{Sa}$ & 0.04 \\
\hline
\end{tabular}

The obtained results showed that No. 22 wind power plant sand (Sa) hydraulic conductivity was significantly higher than that of No. 19 and 9 power plants. The main reason for this is the heterogeneity of the ground in the coldresistant layer at different sites as well as different degree of soil compaction. On No. 22 wind power plant site, the natural density of the investigated soil was only $1.46 \div 1.58 \mathrm{Mg} / \mathrm{m}^{3}$. The results of fillings into arranged gravel layer on sites No. 11, 18 and 22 to determine filtration properties showed a clear inconsistency with the design requirements. The design minimum requirement for the hydraulic conductivity is $0.864 \mathrm{~m} / \mathrm{d}$ or $0.001 \mathrm{~m} / \mathrm{s}$.

For the determination of filtration properties, fillings were made into the cold-resistant gravel (Gr) layer on sites No. 9, 19 and 22. The obtained results showed that the hydraulic conductivity on sites No. 9 and 19 was too low and on No. 22 site the rate of the sand (Sa) hydraulic conductivity was related to the loose soil and soil grain size composition.

\section{Investigation of the state and properties of gravel and cold-resistant layers}

On wind power plant crane installation sites No. 9, 19 and 22, excavations were made to take samples from the cold-resistant layer.

On No. 9 site, three excavations were made at different locations. It was determined that the excavations consisted of three layers. The first layer consists of a layer of compacted gravel and the second layer consisted of cold-resistant sandy soil. This layer is divided into two parts: the first part is made up of fine sand with gravel impurity, and the 
second part is made up of fine sand. The third layer is the foundation of the clay soil. The test of the moisture content of the samples taken from the fine sand showed that the soils in two excavations were highly soaked. From excavations No. 3, 5 and 6, samples of the unbroken structure were taken. The objective is to determine the natural density of the soils and moisture content as well as condition of the natural clay soil (the substrate of the coatings) under the coldresistant layer (the plastic and liquid (Atterberg) limits). The sand samples taken from the upper part of the second layer were not taken from the sand, because of the gravel and cobble in this layer and the high density of this layer. The results of the moisture content and density are given in Table 4.

Table 4. Moisture content and density results on No. 9, 19, and 22 sites

\begin{tabular}{|c|c|c|c|c|}
\hline $\begin{array}{c}\text { Wind power plant } \\
\text { No. }\end{array}$ & $\begin{array}{c}\text { Excavation and layer } \\
\text { No. }\end{array}$ & $\begin{array}{l}\text { Depth, } \\
\text { m }\end{array}$ & $\begin{array}{l}\text { Moisture content } \\
w \text {, part of unit }\end{array}$ & $\begin{array}{l}\text { Dencity } \\
\rho, \mathrm{Mg} / \mathrm{m}^{3}\end{array}$ \\
\hline \multirow{16}{*}{9} & \multirow{2}{*}{ excavation 3 / layer 2} & \multirow{2}{*}{$0.42 \div 0.48$} & 0.055 & 1.86 \\
\hline & & & 0.046 & 1.87 \\
\hline & \multirow{3}{*}{ excavation 3 / layer 3} & \multirow{3}{*}{$0.53 \div 0.60$} & 0.246 & 2.11 \\
\hline & & & 0.308 & - \\
\hline & & & 0.215 & 2.09 \\
\hline & \multirow{3}{*}{ excavation 5 / layer 2} & \multirow{3}{*}{$0.43 \div 0.50$} & 0.138 & 2.05 \\
\hline & & & 0.130 & 2.07 \\
\hline & & & 0.139 & 2.07 \\
\hline & \multirow{3}{*}{ excavation 5 / layer 3} & \multirow{3}{*}{$0.55 \div 0.60$} & 0.128 & - \\
\hline & & & 0.121 & 2.19 \\
\hline & & & 0.117 & 2.19 \\
\hline & \multirow{3}{*}{ excavation 6 / layer 2} & \multirow{3}{*}{$0.50 \div 0.52$} & 0.111 & 2.00 \\
\hline & & & 0.111 & 2.05 \\
\hline & & & 0.129 & 2.06 \\
\hline & \multirow{2}{*}{ excavation 6 / layer 3} & \multirow{2}{*}{$0.60 \div 0.65$} & 0.133 & 2.16 \\
\hline & & & 0.124 & 2.15 \\
\hline \multirow{9}{*}{19} & \multirow{4}{*}{ layer 2} & $0.75 \div 0.77$ & 0.063 & 1.97 \\
\hline & & $0.70 \div 0.73$ & 0.061 & 2.05 \\
\hline & & $0.63 \div 0.68$ & 0.052 & 1.78 \\
\hline & & $0.60 \div 0.55$ & 0.041 & 1.69 \\
\hline & \multirow{5}{*}{ layer 3} & \multirow{5}{*}{$0.85 \div 0.90$} & 0.138 & 1.95 \\
\hline & & & 0.126 & 2.00 \\
\hline & & & 0.138 & 1.98 \\
\hline & & & 0.129 & - \\
\hline & & & 0.128 & - \\
\hline \multirow{6}{*}{22} & \multirow{2}{*}{ layer 2} & $0.40 \div 0.60$ & 0.014 & 1.46 \\
\hline & & $0.70 \div 0.75$ & 0.019 & 1.58 \\
\hline & \multirow{3}{*}{ layer 3} & \multirow{3}{*}{$1.00 \div 1.10$} & 0.145 & 2.00 \\
\hline & & & 0.154 & 2.00 \\
\hline & & & 0.150 & 1.96 \\
\hline & layer $2 \mathrm{a}$ & $0.90 \div 0.95$ & 0.143 & - \\
\hline
\end{tabular}

The obtained results showed that the moisture content of the sand taken from No. 3 excavation was 2 times lower than that of the soil of No. 5 and 6 excavations. The obtained laboratory results of No. 3 excavation show that the substrate was made up of different soils, the soil in No. 3 excavation was significantly more humid ( $w$ varies from 0.215 to 0.308 ) compared to No. 5 and 6 excavations, where humidity is more or less maintained (like natural density). The obtained results allow to state that the hydro geological situation of the site is not uniform, the frost-resistant soil is heavily soaked in No. 5 and 6 excavations, and the clay soil has low density and high humidity in No. 3 excavation. Based on the results obtained, calculating the degree of saturation $S_{r}$ of the 2 nd layer, it was found out that the soil in 
No. 3 excavation was only slightly saturated with water and $S_{r}$ was $0.25 \div 0.29$, while in No. 5 and 6 excavations $S_{r}$ ranged from 0.63 to 0.80 . The clay base in No. 3 excavation, according to the results of the plasticity test, is stiff in consistency $\left(I_{c}=0.906\right)$ and in No. 5 and 6 excavations - very stiff $\left(I_{c}>1.0\right)$.

On No. 19 site, a $1.0 \mathrm{~m}$ deep excavation was made (Figure 1). The excavation consists of three layers. The first one consists of a layer of compacted gravel; the second one consists of cold-resistant layer consisting of sandy soil, which according to grain size is from gravelly sand to low-gravel medium coarse sand. This layer is smooth and reaches the depth of $\sim 0.8 \mathrm{~m}$. The third layer is the base of the clay soil. The results for moisture content and density are given in Table 4. On this site, sandy soil is low in water, $S_{r}$ ranges from 0.17 to 0.43 . Minimum values are fixed in the upper part of the layer, and the bottom is close to wet soil, where $\mathrm{Sr}$ is 0.43 . The clay soil is very stiff according to the consistency test.

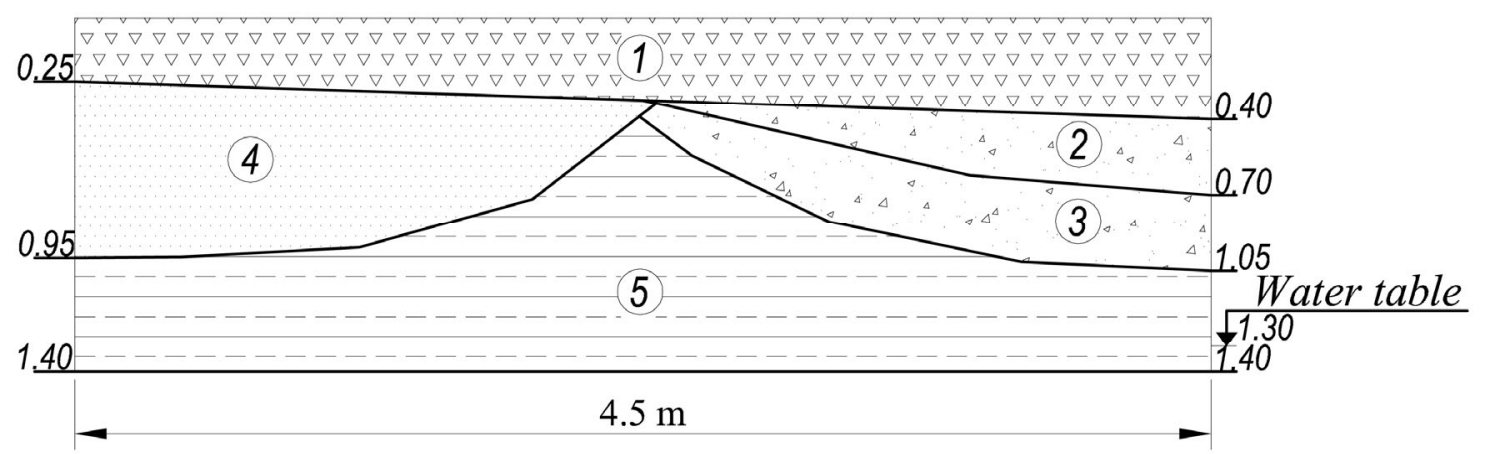

Figure 1. Schematic section of excavation of No. 19 wind power plant: 1 - technogenic gravel;

2 - technogenic gravelly fine sand; 3 - technogenic gravelly fine sand, with clay, saturated; 4 - technogenic coarse sand with cobbles; 5 - natural soil (silty clay, witg fine sand)

On No. 22 site, one $1.2 \mathrm{~m}$ excavation was made. The excavation is made up of three layers. The first layer consists of a layer of compacted gravel; the second layer is made of sandy (loose) soil. This soil is very low saturation, because the grain size of this soil is dominated by coarse fractions while the fines are very low. Layer 2 extends to a depth of $0.90 \mathrm{~m}$ from the existing surface. This layer is even, except for the lower part, where very sandy silt (layer 2a) is found, saturated with water; the thickness of this layer is $\sim 5 \mathrm{~cm}$. It should be noted that the water accumulates in the depths mentioned above, which weakens the entire cold-resistant soil. In April 2015, after digging the ground on the same site, the cold-resistant soil made of fine sand in the lower part was completely soaked. The soil that forms the foundation of the clay is very stiff in consistency but relatively low in density $\left(1.96 \div 2.00 \mathrm{Mg} / \mathrm{m}^{3}\right)$. According to the results of the plasticity test, the consistency of this clayey soil is stiff -0.946 . The results for moisture content and density are given in Table 4.

Dynamic probing light (according to EN ISO 22476-2)

In April 2015, dynamic probing light was applied at different locations on No. 19 and 22 wind power plant crane installation sites, three on each. All three investigations on No. 19 power plant site showed that the upper part of the soil, up to the depth of $0.6 \div 0.7 \mathrm{~m}$, was denser compared to the lower layer, which was much weaker. Having made a $4.5 \mathrm{~m}$ long excavation at a depth of $1.8 \mathrm{~m}$, the groundwater level was recorded at a depth of $1.3 \mathrm{~m}$. The density index $I_{d}$ is calculated only for the upper part and should be considered with care, because having made the excavation, very volatile soil is visually determined. In some places, under gravel, sand or medium coarse sand is loose, but in the middle part of the excavation, there is found a natural clay soil (Figure 1). Therefore, numerical $I_{d}$ values may be inaccurate because the soil in the test site is volatile while the calculation of $I_{d}$ for the clay soil is usually not done.

The results of dynamic probing light investigation of the power plant No. 22 shows that the soil is of medium density, with a slight weakening from the depth of $0.4 \div 0.6 \mathrm{~m}$. Weakness is associated with the groundwater level. After the excavation was made, it was found out that the top of it was made up of a $24 \mathrm{~cm}$ thick layer of gravel and sand beneath it. The excavation depth $-1.20 \mathrm{~m}$. The water settled at a depth of $1.05 \mathrm{~m}$. The results of dynamic probing light investigations are presented in Figure 2.

\section{Conclusions}

- The permeable fraction of the fine fraction has been found to be too high for the explored layer. Based on the data obtained, the permissible fine particle size in the soil $(<0.063 \mathrm{~mm})$ in all samples tested exceeds the permitted $5 \%$ limit. According to the excavation filling results, the values of the hydraulic conductivity $k, \mathrm{~m} / \mathrm{d}\left(T=10^{\circ} \mathrm{C}\right)$ are very low and vary from 0.0073 to $0.028 \mathrm{~m} / \mathrm{d}$. 

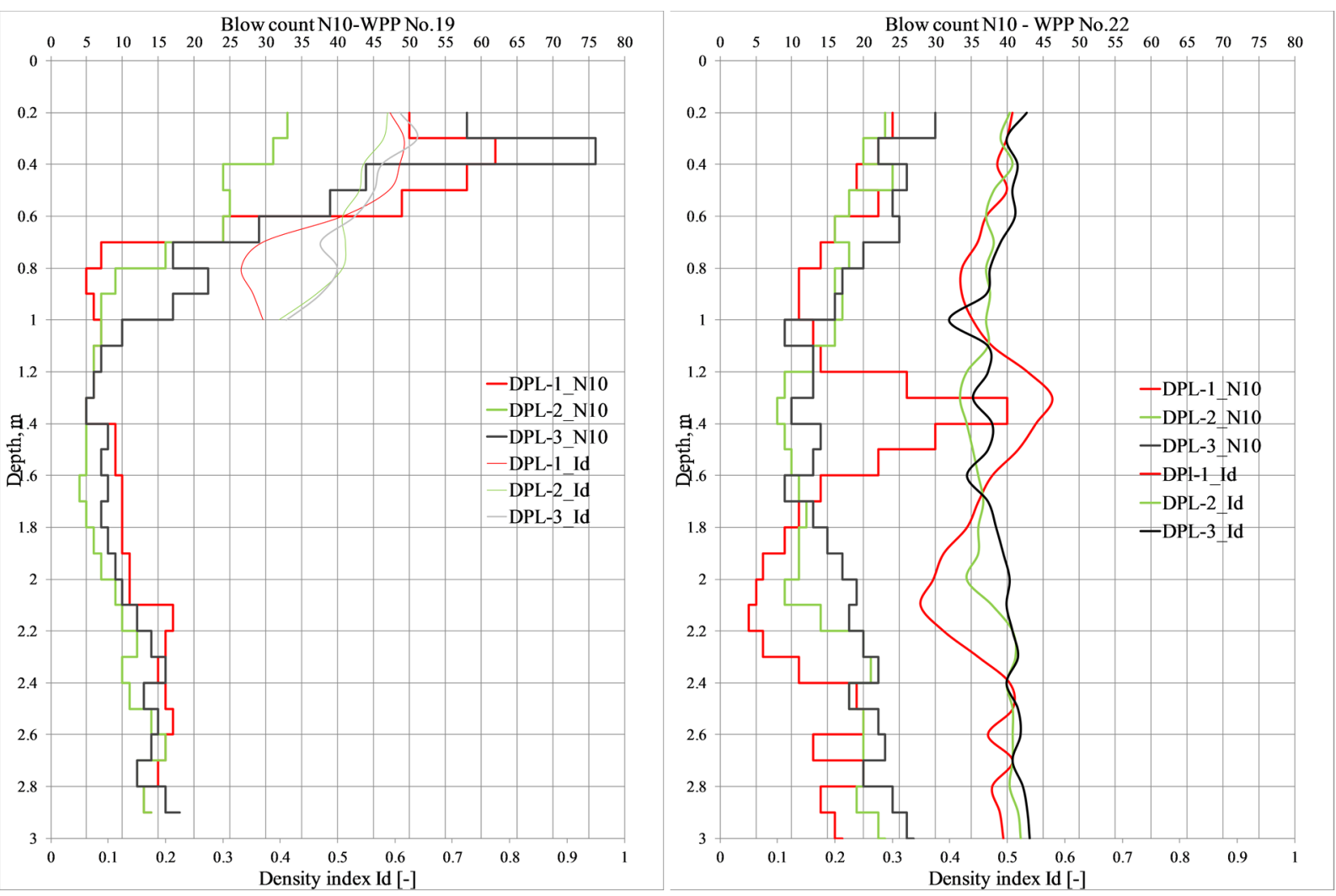

Figure 2. Results of Dynamic Probing Light of the foundations of wind power plants No. 19 and No. 22

- The cold-resistant layer has different grain size distribution on all the investigated sites, it is also not maintained at depth, its degree of saturation also varies not only on different sites, but can also vary on the same site. Hydraulic conductivity $k, \mathrm{~m} / \mathrm{d}\left(T=10^{\circ} \mathrm{C}\right)$ values are very low and vary from 0.04 to 9.39 according to the results of the excavation filling. Site No. 22 hydraulic conductivity is high enough $-9.39 \mathrm{~m} / \mathrm{d}$, but it is associated with sputtered soil (where the natural density was only $1.46 \div 1.58 \mathrm{Mg} / \mathrm{m}^{3}$ ) and due to predominating coarse fraction of soil, which causes soil compaction impossible. The cold-resistant layer contains soil with high variation in composition and properties, even in the construction of the same crane site, which contradicts IT SBR 07. Volatile soil with its grain size distribution (increased impurity of fine particles) results in different water filtration rates from the structure or even soaking of individual layers resulting in loss of strength of the structure.

- The foundation under the cold-resistant layers according to the test result is not soaked. Its consistency ranges from stiff to very stiff.

- The installation crane site constructional solutions provided for a sufficient set of measures to minimize the impact of the spring flood on the construction so that it could last the shortest possible time, although it was not taken into account that carrying out compact work on the installation crane sites during flood can only harm them.

\section{References}

European Committee for Standardization. (2002). Geotechnical investigation and testing - Field testing - Part 2: Dynamic probing (ISO/DIS 22476-2:2002).

Lietuvos automobilių kelių direkcija prie Susisiekimo ministerijos. (2007). Lietuvos automobiliu keliu direkcijos prie Susisiekimo ministerijos generalinio direktoriaus i s a $\mathrm{k}$ y $\mathrm{m}$ a s dèl automobiliu keliu dangos konstrukcijos sluoksnių be rišikliu ịrengimo taisykliu IT SBR 07 patvirtinimo. $2007 \mathrm{~m}$. sausio $30 \mathrm{~d}$. Nr. V-18. Vilnius. https://www.e-tar.lt/portal/lt/legalAct/TAR.E5B3D5F99FCB/asr

Lietuvos Standartizacijos Departamentas. (1995). Automobiliu keliu gruntai. Bandymo metodai. Bandymas štampu (LST 1360.5:1995).

Lietuvos Standartizacijos Departamentas. (2012). Bandymai užpildu geometrinèms savybèms nustatyti. 1 dalis. Granuliometrinès sudèties nustatymas. Sijojimo metodas (LST EN 933-1:2012). 